\title{
El "otro" sendero: los presupuestos teóricos de Hernando De Soto
}

Carlos Gmo. Ramos González

\section{Introducción}

Algunas de las conclusiones fundamentales a las que hemos llegado después de este primer trabajo de investigación, en la mejor de las posibilidades "servirán para orientar futuras investigaciones o reflexiones sobre la materia y, en la peor, para enrumbar críticas y quizás denunciar algún prejuicio"1. Con este senalamiento, entre otros, termina Hemando de Soto su ya famosa obra "El Otro Sencero".

El presente trabajo, por lo demás sin la pretensión de una incuestionable rigurosidad y profundidad, esta orientado hacia la segunda de las posibilidades apuntadas por De Soto. Con ello pretendemos contribuir a una mejor comprensión de las formulaciones y propuestas planteadas por aquel autor. Muy probablemente se nos indicará como una de las mayores debilidades de esta revisión crítica, el insuficiente (o acaso nu10), rescate de los elementos positivos de "El Otro Sendero": sin embargo ella es una debilidad que hemos asumido conciente y deliberadamente.

La temática central de "El Otro Sendero", lo constituye el fenómeno de la informalidad; su origen, contenido y potencialidades. Concomitantemente, y en función de la manera particular en que se ha concebido al sector informal, encontramos una crítica al Estado (que él llama mercantilista o intervencionista), y una específica propuesta de desarrollo para la sociedad peruana (y por extensión latinoamericana).

El sector informal no es un fenómeno nuevo, tampoco un tema nue- 
vo en el terreno de las ciencias sociales. Como fenómeno ha sido objeto de diveras consideraciones teórico metodológicas y, como noción, la resultante de todo un proceso de discusión conceptuar.

Lo novedoso es más bien la centralidad que, con la crisis, ha llegado a asumir la informalidad en el contexto de la actual reflexión de las ciencias sociales latinoamericanas. Todavia más novedosos han sido los esfuerzos con que las corrientes neoliberales que recorren el continente están tratando de adoptar, orientar y monopolizar el tratamiento de este y otros temas; como el de la descentralización estatal, por ejemplo, que en su momento habria sido un patrimonio de intelectuales de izquierda. La seriedad que para el campo popular poseen las implicaciones políticas de estas concepciones es inobjetable ${ }^{3}$. No detenernos en criticas y concienzudas consideraciones de las mismas podría ser imperdonable.

Es en estos esfuerzos y en este auge del neoliberalismo, y de to que se ha denominado la "nueva derecha" latinoamericana, donde se ubica Hernando De Soto y su Otro Sendero. Pérez Sáinz disentirla medianamente de calificar el análisis de De Soto como neoliberal por considerar que sus ataques no están dirigidos al Estado desarrollista, como es 10 propio del neoliberal, sino contra su lógica mercantilista ${ }^{4}$. Sin embargo, nosotros creemos que ello no obsta para que De Soto, como parte de la nueva derecha latinoamericana, comparta de forma precisa los presupuestos teóricos que subyacen a todo el movimiento neoliberal. Todo lo contrario, los supuestos fundamentales de "El Otro Sendero" como los del neoliberalismo en general, podemos encontrarlos a pari en los conceptos claves de la filosofía liberal. Que De Soto sea to más fiel y/o más representativo del actual pensamiento neoliberal es otro problema que no es aquí el objeto de consideración. Lo que si sostenemos es que ocupa un lugar en ese arcoiris de neoliberalismo que se ha levantado sobre América Latina.

Se le ha sefialado, como una de las principales críticas, el reduccionismo que acompana a su determinación precisa del sector informal. De Soto, en lo que sostiene es un análisis empirico de aquel sector, identifica el fenómeno general de la informalidad con el pequeho empresariado no beneficiado directamente por el sistema legal. Esta identificación supone, sefalan Menjivar y Pérez, "una visión reduccionista del fenómeno de la informalidad que soslaya una de sus dimensiones fundamentales: su heterogeneidad"s.

A partir de esta cuestionable homogenización del sector es, para De Soto, relativamente más tácil pensar en su inserción a una estrategia de desarrollo en el marco de un mayor liberalismo económico, como el 
que él propone. Respecto de esta homogenización, aún para el caso de Penú -que es el estudiado por De Soto y donde la informalidad es factualmente impresionanto-, de toda la población inserta en el sector informal, habria que determinar el porcentaje de los que con precisión pueden ser llamados micro-empresarios. Habria que determinar, pues, como primer punto, su representatividad cuantitativa en el sector.

Concomitantemente, habiendo efectuado la reducción sefhalada, De Soto puede sugerir que es el espiritu empresarial lo que impulsa la aparición, crecimiento y desarrollo del sector informal (un espíritu que por lo demás debe enfrentarse al poderoso mercantilismo estatal). Para él, concluye Pérez Sáinz, "todo informal se guia por orientaciones empresariales". Lo que se verifica en el sector es, por lo tanto, una manifestación clara de lógicas de acumulación, he aqui el punto.

Desde un primer momento lo que De Soto se ha propuesto es "explicitar cuál es la lógica de funcionamiento implícita en la informalidad"7. Al concluir, parece tener la convicción de haber encontrado en la lógica de acumulación el principio explicativo de la informalidad. Privilegia de tal modo las lógicas de acumulación que considera una ventaja del sector informal el no estar obligado a cumplir con las leyes laborales y por tanto el poder pagar salarios muy por debajo de los estipulados como minimos, y despedir antojadizamente a los trabajadores. Una ventaja de la informalidad, dice, "es que cuando el mercado se deprime ellos pueden contratar y despedir empleados sin otros inconvenientes que las consideraciones morales (que deben ser pocas) o la desventaja de perder a buenos dependientes"日. Pareciera que para De Soto, los trabajadores de estas empresas no son una parte integral del denominado Sector Informal.

Sin embargo, como ya to han sefialado con suficiente claridad y consistencia otros autores, en la informalidad también se verifican, quizás con mayor peso y representatividad del fenómeno, otras lógicas, estrategías o dinámicas; para el caso es indiferente como se les denomine. Antes que lógicas de acumulación lo que subyace en el fenómeno de la informalidad son lógicas de subsistencia?.

Un caso ubicado en el extremo opuesto a la postura de De Soto es Ortiz. J. L., quien define a la totalidad del sector informal como "un gran sector poblacional, cuya fuerza de trabajo no es absorida por las formas modernas de producción y que debe realizar actividades que le permitan autogenerar ingresos, en una lógica de subsistencia antes que de acumulación"10.

En fin, lo importante es senalar que el sector informal no es, sin más, la resultante de un espiritu empresarial emprendedor que se ex- 
presa pese a las trabas estatales (como sugiere De Soto), sino, principalmente, la expresión con que los sectores populares buscan resolver su necesidad de sobrevivir, en el marco de un modo de producción excluyente.

Cuando De soto piensa y propone una estrategia de desarrollo para nuestros paises, en la cual se inserta decididamente el sector informal; to hace bajo el supuesto de una relativa homogeneidad empresarial del mismo. De esta suerte, no es tanto el fenómeno de la informalidad en cuanto tal al que se estaría insertando; sino a aquel subsector identificable con los pequenos empresarios no acogidos hasta hoy por los beneficios del sistema. Pensar en la insercción de todo el sector informal, con la heterogeneidad que el implica, es un reto aún no encarado.

No es desautorizar aprioristicamente la propuesta de De Soto to que pretendemos. El sector microempresarial, en unas sociedades más que en otras, puede llegar a tener un lugar privilegiado en futuras estrategias de desarrollo. Si ello es una posibilidad, debe ser reconocida con realismo.

Pero bien, en el presente trabajo no nos dedicaremos a reflexionar sobre el problema de la informalidad en cuanto tal. No es su origen, su contenido, sus perspectivas, o el desarrollo que ha experimentado su concepto lo que nos interesa. Tampoco se trata de una consideración factual del fenómeno.

Lo que aqui intentaremos es, más bien, determinar algunos de los presupuestos teóricos que subyacen a De Soto y su "Otro Sendero". Presupuestos que, por lo demás, pese a que él afirme que su categoria de informalidad responde a la observación emplrica del fenómeno", le posibilitan hacer la particular consideración que hace del sector informal (consideración que incluye, fundamentalmente, la reducción del fenómeno y el énfasis de las lógicas de acumulación en la explicación del mismo). Pretendemos también, a partir de la determinación de tales presupuestos, formular algunos juicios críticos en torno a "El otro sendero" y la expresión neoliberal en América Latina.

Para cumplir con nuestros objetivos procederemos el abordaje de la siguiente manera:

A. En primer lugar haremos una breve presentación de lo que constituye y define el pensamiento y la filosofla liberal.

B. En segundo, trataremos de vincular los planteamientos de De Soto en particular, y la nueva derecha en general, con los conceptos claves de la teoria clásica liberal. Esto lo haremos, concretamente, a la luz de la concepción Lockeana. La razón estriba en la representati- 
vidad inobjetable de Locke en el contexto de la tradición liberal.

C. En tercero, y último lugar, haremos una reflexión crítica (que bien podrla calificarse como ético-política) de El "otro" sendero y el neoliberalismo latinoamericano.

Con esto pretendemos aclarar, medianamente, el marco categorial en que se mueve y que subyace a las consideraciones y propuestas de Hernando de Soto.

Estamos en una época en que las propuestas neoliberales parecen estar de moda. La acogida que han tenido en muchos círculos académicos, intelectuales y empresariales es un buen sintoma para calibrarlo. Tal vez se deba a la fuerza con que estas se han presentado, a su aparente novedad o a lo sujerentes que se muestran. La crítica de estas propuestas no parece estar cerca de volverse una moda; sin embargo, ello no es razón para no ensayar crítica alguna, mucho menos para acoger acríticamente sus planteamientos.

Quizás la crítica de todas estas propuestas y proyectos que se promueven y ejecutan en América Latina sea nadar contra corriente; y de hecho lo es. Es nadar contra corriente, pero no contra la historia. Pues sumarse a la corriente no es sumarse a la verdad. Resulta ilustrativa, en este punto, la historieta a la que alude Hinkelammert al referirse a la pretensión neoderechista de imponer su concepción del mundo y la sociedad como verdad absoluta: "la bruja —reza el cuento- envenenó la fuente del pueblo, de la cual todos tomaron agua. Todos enloquecieron, excepto el rey, que no habia bebido. El pueblo sospecho de él, y lo buscaba, para matarlo. Entonces el rey, en apuros, también bebió y enloqueció. Todos lo celebraron por que habia entrado en razón". ${ }^{12}$

\section{El LIberallsmo}

\section{A. La concepclon Ilberal}

Hagamos aqul una presentación general y relativamente simplificada de to que es e implica el pensamiento liberal.

EI liberalismo constituye, a la vez, una ideología, una filosofía, una racionalidad, una sociologla, una ética particular cuyo desarrollo está estrechamente vinculado al desmoronamiento de un orden social y al surgimiento de uno nuevo, del cual será su expresión teórica e ldeologica.

Se trata del progresivo resquebrajamiento del orden feudal y del dosarrollo de una sociedad de mercado que poco a poco irá flltrando y debilitando los fundamentos sociales y conceptuales de aquel orden ca. 
duco. Refiriéndose a los inicios de este proceso, Samour's senala que el aparecimiento del comerciante aventurero en las comunicaciones agrarias de la edad media puede considerarse el simbolo de nuevos tiempos que implicarán progresivamente el paso de una economla local y familiar a una economia de mercado. Su aparición, aparejada al desarrollo del artesanado (y de un nuevo medio social: la ciudad), constituye el surgimiento de un nuevo tipo de hombres que se distinguen claramente de las clases ya establecidas: los nobles, el clero y los campesinos o siervos. Un nuevo tipo de hombres cuyo horizonte deja de estar vinculado al pasado y la tradición, y se vincula más bien a una mentalidad individualista, previsora del futuro y con la esperanza de retribuciones y ganancias.

En esta línea, el liberalismo se configura como la ideologia que va surgiendo de la ruptura con la sociedad medieval y su universo Intelectual en el contexto de condiciones histórico-sociales determinadas, que caracterizaron a la Europa Central de los Siglos XVII y XVIII, y particularmente a la sociedad inglesa.

El liberalismo llego a afirmarse, asl, como una ideologla, como "un conjunto de actitudes mentales, de valores individuales, típicos de la racionalidad occidental... Una actitud racional... que intenta explicar la totalidad de las relaciones humanas a partir de un individuo libre, consciente de su capacidad para desarrollarse y que to puede hacer sin ningún obstáculo a su iniciativa... es una visión de mundo que tiene por principio fundamental la libertad del individuo a todo nivel ${ }^{m 14}$.

El pensamiento liberal es también una filosofia con su propia racionalidad y ética. La nueva racionalidad que irá surgiendo con lo que hoy denominamos filosofía liberal se conforma en la expresión teorico-ideológica del desarrollo de la lógica mercantil. Poco a poco, con la emergencia cada vez más definida de los sectores burgueses y las ideas liberales, la escolástica irá cediendo espacio a sistemas más secularizados de entender la realidad, sistemas en que el universo se concibe en función del hombre. Ahora, el mundo será un mundo "sobre el cual el hombre es libre de actuar según su razón y que podrá reconstruir y conocer para su utilidad"15.

Las primeras formulaciones de esta racionalidad pueden rastrearse por lo menos hasta la filosofía cartesiana, en los albores del modo de producción capitalista. Para Descartes, el hombre por su propia razón es capaz de conocer la verdad, de "tener ideas claras y distintas" de las cosas y por tanto capaz de dominar ese mundo que "no tiene nada de sobrenatural... El universo es un campo dispuesto para que la acción humana racional lo domine y utilice en provecho propio"ie. Asl, es 
este postulado de la racionalidad que se hallan dotados todos los individuos y el correlato real al cual expresa, "lo que irá a trastocar los fundamentos de la sociedad medieval comunitaria y estamentalteocéntrica para volverla individualista, egocéntrica y libera/"17.

A lo largo de su desarrollo, el pensamiento liberal va a ir afirmando y arraigando este carácter de see una filosofia que "sostiene racionalmente la autonomia del hombre en el universo"18. Una filosofia que parte de un concepto de hombre como ser individual que debe afirmar y ejercer su independencia en el universo, de manera especial frente a la sociedad y el Estado. Asi, desemboca "en una filosofía social y política donde el hecho primario fundamental son los derechos fundamentales del hombre (como individuo), y no tanto sus deberes, y para la cual la misión del estado consiste en proteger y salvaguadar esos derechos... Liberalismo se opone a toda forma de estatismo"19.

Este carácter le viene del hecho de que se erige frente a concepciones jerárquicas y teocéntricas del mundo y de la historia, y ante la necesidad de contrarrestar el absolutismo de cualquier poder, sea este religioso, político, económico, etc.; afirmando y privilegiando la autonomia personal y la racionalidad individual como valor máximo. De esta suerte, en el marco de la filosofia liberal "hacemos de lo privado un valor absoluto, convertimos al individualismo en principio de inteligibilidad de los hechos humanos... se puede considerar como liberal toda manifestación basada en la bondad natural del hombre y en la fuerza de la razón, que intente liberar al individuo del peso de cualquier autoridad ya sea religiosa, moral, racional o política, con la intención de asegurar a todos los hombres la posibilidad de afirmar sus derechos y de trabajar por el incremento de sus bienes"20.

Resumiendo, filosóficamente el liberalismo se presenta como "una racionalización de la independencia de los individuos, tendiente a protegerlo de cualquier poder"21.

Ahora bien, como es el ámbito del quehacer económico el lugar por excelencia de la actividad humana; en la sociedad propuesta por el IIberalismo "la única regla y principio que hay que respetar es la fórmula de libre competencia"z2 que asegura y estimula la afirmación y reallzación individual trente a los otros. De aqui que el liberalismo tamblén implique una ética propia. A grandes razgos, pues a lo largo del trabajo irán surgiendo elementos pertinentes a la cuestión, puede afirmarse que la ética que el liberalismo va a impulsar se resume en el esfuerzo por liberar al poseedor de los medios de producción, emancipándolo de toda obediencia a reglas que coarten su explotación eficiente ${ }^{23}$. 
Todo el liberalismo, en cualquier de sus expresiones está vinculado al concepto de libertad. Sin embargo, la libertad con que se relaciona y a la cual promueve, no es de carácter universal, sino restringida a los individuos que poseen propiedad y que, por ende, están capacitados para insertarse en la lógica competitiva y acumulativa del mercado.

Tal estructura fundamental del liberalismo acarrea a la propuesta de establecer democracias liberales (y a las democracias liberales existentes) contradiciones intrínsecas insalvables ${ }^{24}$. Democracia y liberalismo se oponen mutuamente. Tales contradiciones no son, sin embargo, objeto de consideración en este trabajo.

Hemos dicho que entre el siglo XII y XVIII asistimos a un vasto movimiento de descomposición un sistema social y de todas sus coordenadas; economia, política, racionalidad, ética, religión, etc. Pero ello no desemboca en un vacio del cual mágicamente surge la sociedad burguesa ${ }^{25}$. Este movimiento es a la vez de estructuración de un nuevo orden social y económico: la sociedad burguesa; y de un nuevo universo ideológico-conceptual: el liberalismo. Universo ideológico que tendrá sus propios desarrollos en el siglo $X I X$, y que impregnará y asumirá determinadas vertientes de pensamiento en el presente siglo.

No es este el lugar para hacer una revisión de las condiciones históricas que fueron posibilitando que para el siglo XXVII la ideologla liberal echara sus más profundas raíces. Proceso que por lo demás puede remontarse hasta el siglo $X^{28}$. Tampoco para determinar los desarrollos que el liberalismo ha experimentado en los siglos posteriores, especialmente en las versiones del neoliberalismo más reciente. Esta introducción más bien tiene por objeto ubicar grosso modo su signiticado histórico y teórico, para poder entrar a nuestra consideración de los supuestos liberales que subyacen a las formulaciones y propuestas de Hemando de Soto. Sin embargo una revisión del tipo senalado es una tarea urgente en esta época que el liberalismo, bajo distintos y diferenciados ropajes, parece estar alzando vuelo una vez más. Aunque la formulación puede parecer demasiado ideológica, creemos que historizar to que ha constituido el nucleo del liberalismo y sus fundamentos teóricos, es una tarea impresindible para comprender su "esencia" y desenmascarar a todos los neoliberalismos que hoy recorren nuestra América Latina.

\section{B. El supuesto unlflcador}

Acunemos rápidamente una idea más, tratando de no extender lo que hemos pensado como una presentación introductoria de lo que es el liberalismo. Se trata de senalar cuál es el supuesto unificador que 
está a la base de todo el pensamiento liberal, y de sus diversas versiones. Muy seguramente este punto será objeto de morosas repeticiones en el desarrollo del trabajo, así es que aquí nos limitamos a definirlo en lo fundamental.

Al considerar el problema de la unidad subyacente al pensamiemto polftico que se desarrolla entre los siglos XVII y XIX en Inglaterra, Macpherson ${ }^{27}$ lo denomina acentadamente "individualismo posesivo". Es un supuesto que a partir de Hobber y Locke ha persistido y se ha arraigado en todo el pensamiento liberal y democrático-liberal posterior ${ }^{29}$. Las teorias de Bentham, James Mill, John S. Mill, J. Schumpeter, por mencionar algunas, con todas las diferencias que pueden separarlas, se encuentran estrechamente unidas por el cordón umbilical del individualismo posesivo. La misma tesis puede ser aplicable a todas las formas de neoliberalismo a que actualmente nos enfrentamos, entre ellas las sujerentes propuestas de Hernando De Soto. La noción del individualismo posesivo continúa -y continuará- siendo el supuesto central del liberalismo y sus bastagos, por injertados que estos sean.

Aun cuando ditícilmente se le pueda considerar un pensador liberal; "el individualismo como posición teórica básica, se remonta cuando menos a Hobbes"zo, y a partir de él tal posición será una nota característica de la tradición liberal que le sucede. Dejando de lado los conceptos tradicionales de sociedad, justicia, etc., dice Macpherson, Hobber "infirió los derechos y obligaciones políticas del interés y la voluntad de los individuos disociados" ${ }^{\text {"30. }}$.

Las formas concretas en que se desplegará el individualismo posesivo en las diferentes concepciones liberales puede variar, sin embargo el nucleo del supuesto permanece. De una u otra forma la cualidad poseedora (y acumuladora) será central para entender la naturaleza humana (el individuo) y la posibilidad de libertad aparecerá como una variable en función de la posesión (ser propietario). finalmente la sociedad se concebirá como un agregado de individuos en relaciones de mercado (relaciones de intercambio entre propietarios privados).

Esquemáticamente, los postulados centrales del individualismo posesivo ${ }^{31}$ podrian formularse de la siguiente manera:

1. Lo que hace humano al hombre es ser libre de la dependencia de las voluntades de los demás.

2. El individuo es esencialmente el propietario de su propia persona y de sus capacidades (y bienes) por las cuales nada debe a la sociedad). 
3. La sociedad humana consiste en una serie de relaciones mercantiles.

4. La sociedad política es una invención humana para la protección de la propiedad que el individuo tiene sobre su persona y sus bienes, y (por tanto) para el mantenimiento de relaciones de cambio debidamente ordenadas entre individuos considerados como propietarios de sl mismos.

Como se puede observar, el tercer postulado es una consecuencia de los 2 anteriores, pues si la humanidad consiste en la libertad y se es libre "solamente en la medida en que se es propietario de sf mismo, la sociedad humana solamente puede consistir en una serie de relaciones entre propietarios, esto es, relaciones mercantiles" ${ }^{\prime 32}$

Reduciendo aún más los postulados enumerados podemos decir que se concentran en afirmar que el hombre sólo es libre y humano en virtud de la propiedad, y que el orden social es "esencialmente" una sociedad de mercado. Terminemos senalando que estos principios, propios del individualismo posesivo, senalan y reflejan el carácter atomizado de la sociedad de mercado, no su naturaleza de clase. Una sociedad posesiva de mercado "es una serie de relaciones competitivas y hostiles entre los hombres, independientemente de su clase ${ }^{n 33}$. Aunque efectivamente esta sociedad está dividida en clases, lo que los principios del individualismo posesivo reflejan es su carácter atomizado.

Con la certeza de habernos extendido más de lo aconsejable; ponemos ahora a considerar algunas nociones básicas del liberalismo a la luz de las formulaciones Lockeanas, que nos servirán de marco de referencia para ubicar mejor los conceptos que subyacen a las propuestas de la nueva derecha latinoamericana y, especificamente, a "el otro sendero" que nos sugiere Hernando de Soto.

\section{Hernando De Soto y la nueva derecha: Su marco referenclal}

Como ya lo hemos sefialado, en este apartado intentaremos víncular los planteamientos de De Soto y la nueva derecha con los pivotes conceptuales que estructuran y sustentan el pensamiento clásico liberal. Esto lo haremos a la luz de la concreción que adquieren los conceptos e ideas liberales en las formulaciones de J. Locke, en su Ensayo Sobre el Gobierno Civil. Podriamos haber escogido como punto referencial a algún otro reconocido representante de esta tradición; sin embargo la representatividad del filósofo inglés y su enorme y decisiva influencia en todo el pensamiento liberal, prácticamente desde sus orlgenes hasta nuestros dias, constituye suficiente razón para tomarlo como referente en el problema que nos ocupa ${ }^{34}$. Su representatividad co- 
mo uno, sino el máximo, de los exponentes de la filosofía política liberal, es decir del pensamiento burgues, es inobjetable.

Empezaremos por una revisión de los conceptos claves de la filosofía liberal, tal y como fueron acunados por Locke, tratando de senalar cuál sería el "Sendero" cuya idealización esta expresada en aquella filosofia; y posteriormente, intentaremos determinar algunos ejes conceptuales que subyacen a "EI Otro Sendero" para establecer el vínculo que pudiera existir entre la propuesta de De Soto y el pensamiento liberal-burgués.

\section{A. El Sendero del pensamlento llberal:}

Algunas ideas sobre to que constifuye el pensamiento liberal y su supuesto unificador fundamental ya han sido hechas más atrás. Aqui nos dedicaremos a presentar, desde Locke, su concepción de la naturaleza humana y del carácter específico de la sociedad, conceptos, por lo demás, nucleares en su aparataje teórico, y desde los que es posible formular con precisión el sentido del supuesto unificador.

\section{1) Propledad e Indlviduo:}

De lo que se trata es de responder a la pregunta sobre qué es el hombre, en qué consiste la "esencia" humana. Ya se ha dicho que todo liberalismo implica individualismo; también se ha sehalado que la supremacia moral del individuo y el carácter sagrado y absoluto de la propiedad privada individual son dos de sus supuestos básicos. Pero, detengámonos un momento en la cuestión. Hobbes no es precisamente un teórico liberal en sus conclusiones, sin embargo el individualismo como postura teórica básica se remonta cuando menos a él. Hobbes "dejando de lado los conceptos tradicionales de sociedad, justicia..., infirió los derechos y las obligaciones políticas del interés y voluntad de los individuos disociados" ${ }^{35}$, y es que para Hobbes la sociedad no es más que "una serie de relaciones competitivas entre individuos disociados naturalmente y con movimiento propio independiente" ${ }^{136}$.

Locke, por su parte, asume incondicionalmente el individualismo, al punto que es calificado como el padre del individualismo liberal.

Afirmar que la argumentación de Locke representa una justificación de un tipo de sociedad a partir de una concepción naturalista y sustancialista del ser humano, y que su Ensayo Sobre el Gobierno Civil esta escrito contra un sistema de gobierno fundado en los derechos de paternidad o atribución divina, es acertado. Frente a cualquier modalidad de absolutismo Locke busca "la razón del orden de lo social en una "naturaleza" humana, esencial, a la que habrá que atenerse y respetar 
a fin de hacer posible la plena realización del hombre ${ }^{-37}$. De tal suerte que al juzgar sobre las leyes de la sociedad y el estado, afirma que estas "sólo pueden ser justas en cuanto que están fundadas en la ley de la naturaleza, por la que han de regularse y ser interpetadas" ${ }^{23}$. Decir todo esto es acertado, pero no suficiente, veamos más precisamente la argumentación Lockeana.

Locke parte de la idea de un hombre individual, por naturaleza racional y libre respecto de los otros. Inicia su argumentación a partir de un supuesto Estado de naturaleza en que los hombres se encuentan.

Para Locke, este estado de naturaleza es un estado "de completa libertad paraordenar sus actos y para disponer de sus propiedades y de sus personas como mejor les parezca, dentro de los limites de la ley natural, sin necesidad de pedir permiso y sin depender de la voluntad de otra persona"30\%. Se trata de un estado de completa libertad e igualdad. Más adelante, frente a esta igualdad fundamental, Locke se verá obligado a hacer diferencias en facultades, condiciones y racionalidad, al punto que el estado natural del hombre se transformará en un estado natural de desigualdad. Sin embargo este es un aspecto que aqui no se considerará y que, además, no afecta en absoluto nuestro razonamiento.

SI es necesario aclarar que correctamente entendido, "el sentido o significado de este estado de naturaleza no es que haya habido un momento histórico asi, sino que quiere expresar que la naturaleza proporciona unas posibilidades naturales de realizar tal estado. Esto significa que 10 que los individuos son por naturaleza, define ya un sistema de derechos y deberes completo que garantiza los derechos individuales y la convivencia social" ${ }^{\text {"40. }}$.

Ahora bien, a partir del derecho natural atribuido al hombre de disponer libremente de sus actos y facultades, Locke derivará la propiedad privada como nota esencial de la realidad humana. "El hombre -dico- (como dueno de sí mismo y propietario de su propia persona, de sus actos o del trabajo de la misma) llevaba dentro de si la gran base de la propiedad"41. Sin conocer las formas de trabajo comunal y de propiedad colectiva vigentes en otras épocas históricas, Locke, enfatizando la esencialidad e inevitabilidad de la posesión privada de bienes y riquezas, afirma que desde las primeras épocas del mundo "la manera de ser de la vida humana trae necesariamente como consecuencia la propiedad privada particular, porque para trabajar hacen falta materiales en que hacerlo"42.

Introducida de esta forma la propiedad y el acceso a ella como un derecho natural que brota de la esencia misma del ser humano, tene- 
mos que si "cada individuo es dueno de su propia persona, de sl mismo y de todo aquello que él ha empleado o producido para asegurar y conservar su vida y asegurar su bienestar, entonces la propiedad es la condición fundamental para la personalidad y libertad del individuo mas. Razonamiento equivalente encontramos en Hobbes para quien el hombre para ser tal, además de su capacidad de trabajar, debe tener acceso a la propiedad particular ${ }^{4}$. Su humanidad se mide por su capacidad de acceder a la propiedad.

De esta suerte se inaugura una muy particular forma de concebir la racionalidad humana. Dado que se ha postulado la igualdad fundamental de los hombres y se ha erigido a la propiedad en esencia y fin de realidad humana, quienes han fracasado en la consecusión de propiedades y en acumular bienes, pueden tenerse por los únicos aulpables de ello.

Asi como es fundamento de la humanidad, la propiedad es fundamento de la racionalidad. Según Locke, lo que conforma la esencia del comportamiento racional del hombre es la apropiación individual, y como esta puede ser ilimitada resulta que tal esencia es la acumulación. El comportamiento humano está guiado por una lógica de acumulación y sólo quien se acopla a esta lógica es verdaderamente raciona ${ }^{\mu s}$.

Los que no pueden apropiarse de la tierra y las riquezas no pueden ser plenamente racionales, pues no despliegan la esencia de la realidad humana. Racionalidad que el estar medida "en virtud de la mayor - menor posesión de propiedad económica, que depende de ingenio y la mayor aplicación en el mercado"46, remite a una concepción de esencia humana sustraida del modelo de hombre burgués.

Concluyendo, al afirmar la propiedad privada como la esencia humana y a partir de eso justificar su desigual distribución en base a la iniciativa privada individual (paso que aqui no hemos retomado porque nos demoraria aún más); Locke justificó también "como naturales una diferencia de clases en derechos y racionalidad y al hacerlo proporcionó una base moral positiva a la sociedad capitalista"nt. De esta suerte "la plena racionalidad para Locke queda caracterizada por un particular modo de apropiación, al de la acumulación para el lucro del capitalismo naciente de su época y no el de la subsistencia" ${ }^{48 .}$

La propiedad es, pues, en Locke, fundamento de la racionalidad humana $y$, por ende, de la libertad individual ${ }^{49}$. Cualquier cosa, no importa qué, que afecte negativamente la propiedad individual y el derecho a ella puede ser considerado un delito lesa humanidad. De forma original se expresa Hinkelammert sobre esta absolutización de la propiedad privada al afirmar: "Locke pone la propiedad por encima del 
mundo entero. De esta manera y considerando la propiedad privada como ley natural, ley de Dios y del género humano, transforma Imaginariamente toda resistencia en contra de tales relaciones de producción en un acto de agresión en contra del género humano y de Dios mismo"so.

\section{2) Socledad y Estado:}

Veamos muy brevernente el problema del Estado y la Sociedad en Locke. Como se ha venido mostrando, la base de todo el razonamiento Lockeano reside en la centralidad de su teoría del derecho natural a la propiedad individual. El Estado y la Sociedad no escaparán a esta Iógica. Como senala Macpherson, "la afirmación y justificación ... de un derecho natural a la propiedad es fundamental para su teoría de la sociedad civil y el gobierno"s5.

Efectivamente, siendo el hombre esencialmente propietario, la sociedad y el Estado "han de tener su razón de ser en la promoción, protección y defensa de la propiedad privada, de los propietarios: libertad de propiedad, de acumulación individual"52. He aquí el fin fundamental de la sociedad y de Estado. Lo que Locke tiene en mente es en una sociedad de propietarios que se vinculan en el marco de relaciones de mercado (en una sociedad de empresariado difundido, como rezaría la propuesta de De Soto) $)^{53}$ y en un Estado cuya función esencial es la defensa de la propiedad individual (un estado que, contrariamente al burocratizado y reglamentarista estado mercantilista, promueve "buenas leyes", es decir leyes que procuren y hagan vigente el derecho de propiedad, como propondrá De Soto). A lo que asistimos en Locke no es más que a la idealización de un tipo determinado de orden social; la sociedad de mercado ascendente en su época. La idealización del modelo burgués de sociedad.

A riesgo de incurrir en morosas repeticiones, digámoslo una vez mas. La sociedad de Locke es una sociedad de propietarios privados que se vinculan entre si en relaciones de mercado, y su Estado un Estado dirigido a garantizar la vigencia de la propiedad privada y las relaciones de mercado, un Estado de propietarios. Las palabras de Locke no dan lugar a ambiguedad alguna y no necesitan ser interpretadas, "la finalidad máxima -dice Locke-y principal de los hombres que se unen en comunidades, sometiéndose a un gobiemo, es la salvaguardia de su propiedad"54.

Para Locke, sólo una sociedad y un Estado de naturaleza como la que él describe, pueden posibilitar la plena realización y libertad humana. Para él la sociedad burguesa, con las relaciones de intercambio y 
lógicas de acumulación que supone, es el ámbito "natural" del hombre y el terreno en que puede y debe realizar su plena personalidad y libertad. Pero, "la esencia de la libertad... que se predica es, precisamente, la libertad de acumulación" ${ }^{m 5}$, libertad de propiedad y apropiación.

En fin, en Locke, al igual que su concepto de individuo humano, su concepción de la sociedad y el Estado han sido construidos en función del supuesto derecho natural a propiedad privada individual. En función de aquel supuesto que da unidad a todo el pensamiento liberal: el individualismo posesivo.

\section{B. El "otro" sendero y el pensamlento de la nueva derecha latlnoa- merlcana}

Habiendo recorrido ya un buen trecho, vamos a pasar a ver de forma más concreta algunas de las consideraciones y propuestas de De Soto en función de senalar los supuestos teóricos que le subyacen. Ya se ha insinuado algo al respecto, pero aqui trataremos de abordar la cuestión con mayor particularidad.

Antes que nada debemos reconocer que no sin impreciones, pero por razones puramente prácticas, vamos a identificar a la nueva derecha latinoamericana con el pensamiento neoliberal que ha inundado nuestro continente.

Como sabemos "El otro Sendero" es una sujerente y particular interpretación de lo que ese implica el fenómeno de la informalidad. Lo que nosotros enfatizaremos, como ya se ha senalado, es una consideración del marco conceptual referencial desde el cual se ha elaborado aquella interpretación.

\section{Propledad e Indlviduo:}

La opción de De Soto por una concepción individualista del ser humano, es suficientemente clara y fundamental como para permear la totalidad de su perspectiva de análisis e interpretación. Su propuesta misma de desarrollo gira sobre la base de concebir al hombre individual y aislado como el centro y el motor de la sociedad. Traduciendo fielmente la postura de De Soto respecto de lo que considera es la opción de los informales, y que no es sino una remisión de su propia opción Vargas Llosa escribe: ellos han optado "no por el colectivismo... sino por devolver al individuo, a la iniciativa y a la empresa privada, la responsabilidad de dirigir la batalla contra el atraso y la pobrezanse. Nos entrentamos, sin lugar a dudas, a un individualismo en la línea que lo ha venido formulando el pensamiento liberal. 
Hay en De Soto un claro individualismo, donde la acción individual es considerada como racional y portadora de derechos. A lo largo de su obra argumentará repetidamente que el Estado no debe obstruir "la acción de los ciudadanos, pues estos saben mejor que nadie to que quieren y lo que les conviene"57, y lo que quieren, lo que buscan, lo que necesitan, afirma De Soto refiriéndose a los informales, es "realizar las mismas actividades que los formales" ${ }^{50}$; es decir convertirse en empresarios privados, desplegar su "natural" iniciativa individual. Como la ilegalidad vigente no se los garantiza, anade, "han tenido que inventar nuevas formas institucionales para sobrevivir al margen de ella"50; para sobrevivir, en la lógica de De Soto, como empresarios individuales.

En De Soto, como en todo el pensamiento neoliberal, la opción por el individuo es tal que frente a la eficiente iniciativa individual, el carácter ineficiente, corrupto y obstructor del Estado se nos presenta como verdad axiomática ${ }^{\circ 0}$. La radicalidad de este elemento característico de la nueva derecha intelectual, dice Moncada comentando algunos autores, llega al punto que "aún en el caso excepcional en donde el estado sea eficiente, su acción es nefasta desde el punto de vista ético, pues cercena el desarrollo de las libertades individuales" ${ }^{n 1}$. Con la nueva derecha, el individuo se postula una vez más como el sujeto del proceso social ${ }^{62}$.

El sector informal no es, para De Soto otra cosa que la expresión de la natural iniciativa individual intrinseca a la realidad humana; el despliegue más que subterráneo de un "natural" y ahistórico espiritu empresarial. El enfoque neoliberal escribe Cartaya "Identifica en el sector informal la manifestación del espiritu empresarial ahogado por la excesiva regulación estatal de las actividades económicas, lo que lo obligará a actuar al margen de la ley"63. Lo que se descubre en él, como ya se ha dicho y se volverá a sugerir, son lógicas de acumulación, no de subsistencia.

Ahora bien, de la misma forma que la centralidad del individuo, los derechos de propiedad son un elemento constitutivo en la argumentación de De Soto en su "Otro Sendero". Algo se ha dicho ya al respecto, pero quedan varios aspectos que indicar.

De acuerdo a De Soto, la racionalidad del movimiento de los informales peruanos (la vanguardia de "El Otro Sendero"), está orientada por la búsqueda de vigencia efectiva del derecho a la propiedad individual. La historia de los informales es la historia de la lucha por el derecho a la propiedad privada.

La historia de la vivienda, el comercio y el transporte informal, los tres casos estudiados por De Soto, pueden resumirse en la historia de 
la lucha por la propiedad. Veámoslo en sus palabras: "La historia de los asentamientos informales -dico- es la historia de la lucha por acceder a la propiedad privada"es. A su vez, "la historia del comercio informal es la historia de un largo camino... hacia los marcados, que representan la aspiración popular por obtener una propiedad privada segu$\mathrm{ra}^{\text {mos. }}$. Lo mismo puede decirse en el caso del transporte, pues el nucleo de su lucha se encuentra en conquistar el derecho de apropiación de rutanes.

De esta suerte, como bien lo apunta Mirko Lauer "El otro sendero alude a cosas como la vivienda sin titulación de las barriadas, el derecho al comercio ambulatorio, el derecho a un trámite mínimo para constituirse en empresarios formales, 0 aún al derecho de vincularse libremente al mercado de trabajo en condiciones de desventaja. El concepto de propiedad adquiere asi un carácter universal por fuera del Estado" ${ }^{\text {mp }}$. Pero aún más, las invasiones de terrenos, calles y rutas que De Soto estudia, sugiere constituyen la expresión de una "tendencia natural" de hacer vigentes los derechos de propiedad ${ }^{86}$. Por ello es que en la normatividad extralegal surgida de las actividades informales podemos constatar que "lo que buscan los peruanos es, en primer lugar, afirmar derechos de propiedad"69.

Por derechos de propiedad, dice finalmente De Soto, entendemos "todos aquellos ... que reconocen a sus titulares la enajenabilidad y exclusividad sobre los mismos; es decir, la potestad de disponer libremente de ellos y la posibilidad de utilizarlos con exclusión de todos los demás o disfrutarlos libremente ${ }^{m 70}$. Definición que bien podria remitimos a aquel "estado de completa libertad para ordenar sus actos y para disponer de sus propiedades y de sus personas como mejor les parez$\mathrm{ca}^{\mathrm{n} 71}$, en que consiste el Estado natural del género humano descrito por Locke. Estos derechos estarian orientados, pues, desde la perspectivaLocke, a garantizar el Estado Naturaleza y el derecho "natural" a la apropiación privada y su libre disposición.

Con todo, la concepción de hombre en De Soto constituye un retorno y/o rescate del modelo de hombre idealizado por la tradicion filosófica liberal: el modelo de hombre burgués.' Se trata de un modelo individual, libre y poseedor de ser humano; de un hombre que se define como propietario individual, con espiritu emprendedor y libre de ataduras. Se trata, en fin, de una idealización del propietario privado y de la iniciativa empresarial individual.

Asi, en su análisis de la informalidad, el pueblo es descrito por De Soto "no como un conjunto de pobres, sino como sector privado popu$\operatorname{lar}^{\prime 72} y$, por ende, como propietarios privados -como microempresa- 
rios, diremos más tarde- de origen popular. Pero el acento no está en su origen sino en el espiritu empresarial que les mueve.

Con De Soto, y la nueva derecha, todo parece indicar que asistimos a la reivindicación de aquel ideal del empresario emprendedor de Shumpeter, el ideal del empresario que innova arriesga y crea rique$\mathrm{za}^{73}$. Con ello, a su vez, como ya se indicó, el concepto burgués de ser humano vuelve a surgir con incuestionable fuerza y vigor corno uno de los presupuestos teóricos fundamentales del actual pensamiento de la nueva derecha y sus "otros" senderos.

\section{Socledad y Estado}

La concepción de sociedad y estado en De Soto, y el neoliberalismo en general, no escapa a la centralidad de la propiedad privada individual como factor explicativo y fundante. En "El otro Sendero" hay una cantidad impresionante de formulaciones orientadas en este sentido. Aquí sólo traeremos a cuenta algunas que pueden resultar ilustrativas.

En el marco de su critica al Estado mercantilista que él define como un estado "burocrátizado y reglamentarista que antepone el principio de redistribución al de la producción de la riqueza"74, De Soto sostiene que el intervencionismo estatal en el Perú ha sido tal que "en el sentido cabal de los términos, el Perú nunca ha sido un pais de propietarios sino a lo sumo de usufructuarios"75. He ahi el problema y el origen de la pobreza y el subdesarrollo.

Si de una transformación que posibilite el desarrollo social y la plena realización humana se trata, la misión del Estado, dirá De Soto, es hacer "un cambio en las instituciones legales, que asegure una difución masiva de la propiedad y otorgue la seguridad de que cualquier penano podrá tener título incontrovertible sobre ella y aprovechar los beneficios legitimos que resulten de invertir trabajo o capital en su desarrollo"78. La razón no estriba en arbitrariedad alguna; todo lo contrario. Ella deriva de la razón de la existencia misma del Estado, de su 'esencia".

El origen y finalidad de la existencia del Estado y del sistema legalinstitucional que de él se desprende, dirá categóricamente De Soto, "es proteger los derechos individuales y la propiedad frente a terceros, permitir un acceso ordenado a la actividad productiva y facilitar la interacción en forma armoniosa con otros individuos"r. Tal aseveración no se encuentra nada lejos de la ya citada afirmación Lockeana de que "la finalidad máxima de los hombres que se unen en comunidades, sometiéndose a un gobierno es la salvaguardia de su propiedad"78. 
Poco hay que decir sobre el asunto, las citas son suficientemente claras. La vigencia efectiva de la propiedad individual es el nucleo explicativo de la existencia estatal. La sociedad en que piensa De Soto es una sociedad de propietarios privados vinculados por relaciones de intercambio, una sociedad de mercado. La función del Estado es, entonces, asegurar el libre juego del mercado, no intervenir en forma alguna en la dinámica de los factores productivos ${ }^{70}$. Su tarea no se encuentra en administrar algún recurso, sino en garantizar libres y ágiles relaciones de mercado ${ }^{80}$.

Toda esta concepción se encuentra subyaciendo a su análisis e interpretación del sector informal. La informalidad de De Soto está filtrada hasta la médula por su individualismo y su concepción de la sociedad de mercado como la sociedad natural e ideal. El peso de estos presupuestos es lo que explica que entienda a la informalidad "como la mayor evidencia de la necesidad de regresar a un modelo competitivo de regulación de los mercados, desechando definitivamente las políticas de corte Kaynesiano"日1. Para De Soto, la fecundidad que han mostrado los informales es una muestra de "lo que cabria esperar si toda esa energía productiva pudiera desplegarse libremente, en una auténtica economia de mercado, no transgrediendo la ley, ni acosada por el estado-gobierno, sino amparada por aquella y promovida por este ${ }^{\text {nel }}$. Si ello no representa un retorno al liberalismo dificilmente puede ser calificado de otra manera.

Es sobre esta base y sobre estos presupuestos que se entiende mejor su concepción del desarrollo y su propuesta específica para lograrlo. El fundamento del desarrollo se encuentra en la vigencia efectiva de la propiedad privada, de la iniciativa empresarial y las relaciones de mercado. "En verdad - dice De Soto- los empresarios competitivos, formales 0 informales son una nueva cultura... y son una mejor base para emprender una política de desarrollo que los negociantes de privilegios y las burocracias escépticas... pues... su capacidad de arriesgar y calcular es importante porque significa que el pais ya está creando una base empresarial amplia. En el Perú la informalidad ha convertido a una gran cantidad de gente en empresarios... este es el fundamento de cualquier proceso de desarrollo... por que la prosperldad no es otra cosa que la posibilidad de combinar recursos intercambiales en base al trabajo productivo. La prosperidad se alcanza fundamentalmente gracias a un esfuerzo propio. Se gana poco a poco dentro de un mercado activo donde se intercambien bienes, servicios, ideas y donde la gente esté continuamente aprendiendo y dispuesta a ajustarse a las necesidades de los otros". 83 . 
Lo que De Soto propone es una sociedad de mercado pleno, una sociedad de propietarios privados. El objetivo, escribe De Soto, "serla una economia de mercado moderna, que hasta ahora es la única receta conocida para lograr el desarrollo en base a un empresariado difundido"es. Desarrollo que, por lo demás, debe ser medido "en términos de perdidas y ganancias ${ }^{\text {Mes }}$, es decir a través de las categorias del mercado, y no en términos de justicia, de satisfacción de las necesidades básicas o de existencia de aceptables niveles de vida y de reproducción para las mayorías populares.

Aún más, sólo esta sociedad de "empresariado dífundido" puede garantizar el carácter "democrático" del orden social, otra razón para su urgente necesidad. Sólo "si cada ciudadano puede en la práctica ser empresario, cualquier sea su origen, color, sexo, profesión u orientación política, entonces tendremos una economía auténticamente democrática, es decir, una econmia de mercado"日8 concluye De Soto.

He aqui las líneas fundamentales que conforman "EI Otro Sendero". Se trata de una sociedad de mercado basada en un "empresariado difundido". De una sociedad en que los propietarios privados son la norma, y los informales uno de sus renglones estratégicos. Se trata, pues, de una Sociedad en que el eje fundamental lo constituyen los pequenos propietarios y empresarios, una sociedad de micro empresarios en macro competencia.

\section{Reflexlones finales}

Cerremos con algunas reflexiones puntuales nuestro mediano análisis crítico de los presupuestos teóricos que subyacen a "El Otro Sendero" propuesto por De Soto. Avancemos sin mayores rodeos en esta tarea.

No es un fantasma lo que recorre América Latina. Se trata más bien de un mito; de un ya centenario personaje mítico que hoy calza nuevas sandalias y viste nuevo ropaje. Se trata de la idealizada figura del emprendedor empresario individual creador de la riqueza y el progreso; del mito creado por los clásicos liberales del siglo XVII. A ese nuevo grupo de cuentistas que se ha dedicado a ponerlo de moda una vez más en esta enorme caverna que ya platón describió, se ha dado en llamarlos la Nueva Derecha. Entre ellos, y sin falta, Hernando De Soto.

Ahora bien, lo mejor de la verdad de esta figura mítica que recorre nuestro continente, como en todo mito, solo existe en la imaginación de los que en ella creen y la proclaman. Ello es reconfortante. 


\section{A. La Informalldad:}

Como ya se ha dicho insistentemente, para De Soto los informales representan la expresión clara del espiritu empresarial individual ahogado por el intervencionismo estatal. A partir de esta premisa. De Soto elabora su sugerente y explícito programa de introducir a los informales como el renglón estratégico de ese "empresariado difundido" que sería la base del desarrollo Latinoamericano. Subyaciendo a su propuesta encontramos otro programa que no aparece explícitamente pero que él comparte con toda la nueva derecha. "El programa no escrito de la nueva derecha -dice Lauer-... incluye... la exigencia de que se reconozca que la esencia de la naturaleza humana es el egoismo individualista, que los sectores menos humanistas de la burguesía llaman "libertad" en abstracto" ${ }^{\text {"7 }}$. Subyaciendo, pues, encontramos la tesis del individualismo posesivo como la base de su "otro" Sendero.

Sin embargo, lo que De Soto no logra enfocar, dados los lentes teóricos con que se enfrenta al problema, es que la manifestación de la "espontánea" iniciativa empresarial y la lógica de acumulación que ella supone, no son ni lo único, ni lo representativo de la informalidad. Lo que, aún ambiguamente, se ha denominado Sector informal no representa en lo fundamental el despliegue de un supuesto espiritu empresarial, mucho menos de aquel que se identifica con la iniciativa privada capitalista. Nada más alejado de la realidad. Algo de esto podría haber, pero ello es más la excepción, no la regla.

Antes que eso, por lo menos en la mayoria de nuestros países Latinoamericanos y en lo grueso del fenómeno, la informalidad representa estrategias, lógicas, o dinámicas a las que las mayorias populares de nuestro continente echan mano para sobrevivir, aún cuando ello sólo sea en condiciones infrahumanas y/o de subsistencia.

No es un supuesto "prejuicio antiempresarial" ${ }^{88}$ lo que sustenta nuestra crítica. Creemos que los hechos son suficientemente solidos como para vernos obligados a recurrir a algún prejuicio de esa naturaleza para cuestionar la propuesta de De Soto.

Pues bien, antes que lógicas de acumulación, la informalidad representa dinámicas de subsistencia que se constituyen en denuncia de un orden incapaz de garantizar el acceso a los medios fundamentalmente de reproducción material - no digamos espiritual- de la vida a la mayor parte de la población, un orden incapaz de generar vida (en abundancia como diría la máxima evangélica cristiana) para las mayo. rías populares.

Pero, en fin, para De Soto los informales continuan siendo la ma- 
nifestación más clara, del espiritu privado empresarial que no se doblega ante el estado intervencionista y redistribuidor de la riqueza. Los informales no son un problema; son, más bien, la solución. El problema es el Estado.

\section{B. La nueva derecha y el mercado total:}

"Si son muchos los "anti" que definen el pertil de la nueva derecha (anticomunismo, antipopulismo, antitercermundismo, antisindicalismo...), no hay otro tan próximo a la unanimidad entre sus diferentes corrientes como el anti-estatismo"вs. Es algo que hemos venido sefialando desde las primeras páginas. Pero no sólo ello, como también hemos insinuado, al compás de la predica neoconservadora "un cierto fetichismo del mercado se ha ido extendiendo paralelamente entre vastos sectores de la opinión pública... que pretende convertir en gran regulador de la actividad económica de nuestros pais a mercado"so.

Con la nueva derecha asistimos a una nueva idealización de la sociedad de mercado. El mercado y su automatismo es, para ella, el único garante de la libertad y el desarrollo humano y social. "La empresa privada produce libertad (reza el lema)... Asi... cuanto más mercado, más libertad. Cuanto más Estados, menos libertad"91. Debemos permitir, por tanto, que las fuerzas y las leyes del mercado actuen libremente, que este se exprese como la "institución total, infalible y perfecta" ${ }^{\text {"92 }}$ que él es.

El mercado se configura, para la nueva derecha, como el terreno de interacción natural de los individuos al punto que, escribe Lechner, "los cambios sociales son aproximaciones a la verdadera naturaleza 0 interferencias y desviaciones... Es decir, podriamos perfeccionar los mecanismos del mercado o distorsionarlos, pero no podriamos modificar las leyes del mercado"se. El Estado, por su parte, no es sino "el garante exterior de esa integración previa"en y natural en el mercado.

Pues bien, el problema de la pobreza y el subdesarrollo de los países latinoamericanos estriba en la falta de espontaneidad de las fuerzas del mercado; en la no vigencia de una auténtica economia de mercado. Una de las tesis centrales de "El Otro Sendero" esta orientada precisamente en esta dirección, "el Perú - según De Soto- jamás tuvo una economia de mercado y ...solo ahora, gracias a la informalidad, aquella comienza a abrirse paso"gs. Es la falta de un mercado pleno y total el origen de todos los problemas de que adolecen nuestras sociedades.

Hinkelammert resume atinada y precisamente esta posición. El neoliberalismo actual, dice Hinkelammen, "toma en serio de una manera 
completa, nueva y dogmática la idea del automatismo del mercado... declara que las crisis económicas no son consecuencias del automatismo del mercado, las que hay que enfrentar por correcciones del mercado e intervenciones, sino que son consecuencia de una implantación insuficiente de ese automatismo... lo que hace falta es solamente imponerlo en términos totales y perfectos. La realidad (pobreza, desempleo, subdesarrolo...) no se arregla por al solución concreta a estos problemas, sino por la extensión de los mecanismos del mercado sacrificando esta solución" 96 . Con ello, se cae en la "trampa viciosa de que el mal no radica en el sistema, sino en su no vigencia efectivamo7.

Una consecuencia de esta visión totalizadora del mercado es que el conflicto que se verifica en la sociedad, no se presenta como una pugna de intereses de clase, o como una lucha entre el trabajo y el capital; sino, más bien, como un conflicto entre el mercado y sus perturbadores: los estatistas de cualquier género, socialistas o Keynesianos, subversivos o mercantilistas.

En fin, es en esta perspectiva y a partir de las posturas y supuestos senalados que De Soto podrá afirmar que dentro de las fronteras del Perú, existe más de un pais, uno es el mercantilista, el otro el de la violencia terrorista y el tercero, con el cual suena e idealiza como en su momento to hicieron los clásicos liberales hace 3 siglos, es el que constituye "lo que nosotros llamamos "el otro sendero": el pais que trabaja duro, es innovador y ferozmente competitivo y cuya provincia más resaltante es, por supuesto, la informalidad"90.

Es un pais, como bien lo enfatiza él, "ferozmente competitivo"; es, en la terminologia que hemos venido usando, una sociedad de mercado pleno cuyo núcleo lo constituye el individualismo posesivo. Transitar por este sendero, tal y como lo propone De Soto, es hacer de la famosa proposición hobbesiana de bellum omnium contra omnes, la formulación precisa del principio motriz del desarrollo social.

\section{El "Otro" Sendero}

Fascinada con tan clara, evidente y mágica concepción del mundo, en que el automatismo del mercado (el mercado total) se convierte en y por si mismo en la solución óptima a todos los problemas, sin tener que acudir a solución concretas para cada uno en particular, escribe Hinkelamment, "la nueva derecha se lanza, como corresponde, al "otro sendero". Efectivamente no es más que otro sendero y posiblemente el peor. Pero lo que hace falta no es otro sendero; con uno basta... soluciones hacen falta, no otros senderos" ${ }^{\prime 9}$. 
No es más que otro sendero, y posiblemente el peor, dice Hinkelammert. Pérez Sáinz, con mayor radicalidad en este punto, formula sujerentemente su cuestionamiento: informalidad urbana, pregunta, "¿Cuál Sendero?" ${ }^{100}$. Nosotros coincidimos con Hinkelammert en que se trata de "un sendero", pero a diferencia suya, no creemos que sea "otro". A menos que de lo que se trate sea de diferenciarlo de "Sendero Luminoso", 10 cual evidentemente no parece ser el punto. Parafraseando a Pérez Sáinz, nosotros preguntarlamos: informalidad urbana ¿cuál "otro" sendero"?

El "otro" sendero no es tal, es el mismo con que en su momento sonaron los liberales del siglo XVII, formulado de forma medianamente distinta. Se trata del mismo sendero con diferente asfalto, del mismo sendero convertido en una super-carrera donde el carro del mercado pueda desplazarse espontánea y libremente, sin túmulos, sin semáforos, sin policlas.

El sueno de los liberales ha vuelto a resurgir, y esta vez con mucha fuerza en nuestra América Latina. Sonar, en sl, no es malo, todo to contrario. Pues los suenos pueden ser, y han sido, grandes fuentes de utoplas de un mundo libre y justo. Pero este, en particular, es un sueno que puede convertirse en una de las peores pesadillas para las grandes mayorias de nuestro continente si su no vigencia plena y efectiva ha sido suficiente para ocasionar la marginación y la pobreza que caracterizan a nuestros pueblos, qué podrla esperarse de su vigencia total.

En fin, las propuestas neoliberales y sus "otros" Senderos constituyen hoy la expresión de las tendencias dominantes. Su inobjetable vigor en buena aparte alimentado, no precisamente con inyecciones morales, por las instituciones financieras internacionales, está demás sefalarlo. En este contexto sólo cabe esperar (e impulsar) la creatividad de los sectores populares para infiltrar y resemantizar estas propuestas y procesos, en función de un proyecto de liberación.

Cuáles sean los "Otros Senderos" alternativos para nuestros paises, es algo que sólo las ciencias sociales, económicas y humanistas pueden responder en cada caso concreto, y no siempre sin imprecisiones. Por lo pronto, como lo hemos apuntado en otro lugar, "a la filosofla lo que le corresponde es la dificil tarea de liberar a los hombres y a las sociedades de los dogmatismo que niegan su realidad concreta"101. 


\section{NOTAS BIBLIOGRAFICAS}

1. De Soto Hernando, El Otro Sendero. Editorial La Oveja Negra, Bogotá, Colombia, 1987. Pág. 311.

2. Una muy buena, aunque breve revisión del surgimiento de la noción de "informalidad urbana" a partir de las criticas a la teorla de la marginalidad, y de las principales líneas de reflexión que han figurado y configurado el debate actual puede encontrarse en Pérez Sáinz, J. P. "Informalidad Urbana", (debate Latinoamericano y perspectivas de análisis en Guatemala), Debate № 1, Flacso Guatemala 1989.

3. Consideraciones atinadas y sugerentes al respecto son formuladas por Corraggio, en "Poder Popular, ipoder local?". Ver Coraggio, J. L. Descentralización y Poder Local. Centro de Investigaciones CIUDAD, serie textos № 11; Quito, 1989.

4. Pensamos, dice Pérez Sáinz, "que tal calificación es inadecuada y subestima la potencialidad del discurso de De Soto. Su ataque no es contra el Estado desarrollista (de inspiración capitalina), blanco de los ataques neoliberales, sino contra su lógica mercantilista cuyas ralces históricas serlan anteriores". Pérez Sáinz, J. P., Respuestas Silenciosas, (proletarización urbana y reproducción de la fuerza de trabajo en América Latina), Editorial Nueva Sociedad; Caracas, Venezuela, Flacso-Ecuador 1989. Pág. 23.

5. Menjlvar L. y Pérez Sáinz J. Informalidad Urbana en Centroamérica; Flacso - Guatemala, 1989, Pág. 14-15. En un sentido más amplio Vannesa Cartaya señala como definir al sector informal a partir de dicotomias ha conducido a oscurecer la heterogenidad del sector. Vannesa Cartaya, "EI Confuso Mundo del Sector Informal", Nueva Sociedad. Caracas № 90. 1987.

6. Pérez Sáinz J. Respuestas Silenciosas; op cit. Pág. 24.

7. De Soto Hernando. El Otro Sendero; op. cit. Pág. 15.

8. Ibid. Pág. 202.

9. Veáse Menjlvar L. y Pérez Sáinz J. op. cit. Pág. 15; también Pérez Sainz, Respuestas Silenciosas, op. cit. p.p. 24-26.

10. Ortiz J. L. "El Sector Informal Urbano". Citado por Pérez Sáinz, Respuestas Silenciosas, op. cit. Pág. 24.

11. "La noción de informalidad que utilizamos en este libro es, pues, una categorla creada en base a la observación emplrica del fenómeno". De Soto, H. El Otro Sendero; op. cit. Pág. 12.

12. Hinkelammert, Franz J. "Democracia y Nueva Derecha en América latina". Nueva Sociedad, Caracas, Venezuela, № 98. 1988. Pág. 112.

13. Samour, Héctor. Democracia, liberalismo y derechos humanos". UCA, Instituto de Derechos Humanos (IDHUCA). San Salvador, El Salvador 1987, p. p. 5-6.

14. Samour, Héctor. Ibid. Pág. 1.

15. Ibid. Pág. 11.

16. Ibid. Pág. 11. 
17. Cañas, Antonio-Ramos, Carlos G. Elementos para la critice del modelo liberal de democracia en El Salvador desde algunas categorlas antropolbgicas de Mara y Zubiri. Tesis de Licenciatura, UCA, San Salvador, EI Salvador, 1988.

18. Samour, Héctor, op. cit. p. 1.

19. Ibid. p. 2.

20. ibid. p. 3.

21. Ibid. p. 2

22. Ibid. p. 2

23. Ibid. p. 12

24. Un magistral tratamiento de la cuestión ha sido desarrollado por Wolfe, Alan, en los IImites de la legitimidad.Siglo XXI. editores, México 1987.

25. Samour, Héctor. op. cit., po. 17.

26. Ver Samour, op. cit.

27. C.B. Macpherson. La teorla politica del individualismo posesivo. Segunda edición, Editorial fontanella, Barcelona, 1979.

28. C. B. Macpherson, Ibid. p. 13.

29. Ibid. p. 15.

30. Ibid.

31. Tales postulados han sido tomados de los siete que enumera Macpherson para caracterizar al individualismo posesivo. Op. cit. 225-226. nosotros sólo hemos retomado 4 por considerarlos centrales.

32. C. B. Macpherson. Ibid. p. 226.

33. Ibid. p. 231.

34. Cfr. copleston, F., Historia de la filosofla. Volumen 5; México. Editorial Ariel, 1983. p.p. 136-139.

35. C. B. Macpherson op. cit. p. 15.

36. Ibid. p. 27.

37. Cañas, A. Ramos C.G. Op. cit. p. 29.

38. Locke, J. Ensayo sobre el gobierno civil. Madrid: Aguilar, 1973. p 11.

39. Ibid. p. 5.

40. Samour H. op. cit. p. 21.

41. Locke, J. op. cit. p. 35.

42. Ibid. p. 28.

43. Samour, H. op. cit. p. 24.

44. El razonamiento de Hobbes es presentado integralmente por Macpherson, op. cit. p. 58.

45. Ver Macpherson, op. cit., p. 197 y sig.

46. Samour, H. op. cit. p. 50.

47. Macpherson op. cit. p. 191.

48. Cañas, A. Ramos, C.G. op. cit. p. 36.

49. Macpherson, Samour, H. y Cañas. A. Ramos, C.G., consideran con amplitud este aspecto.

50. Hinkelammert, Franz J. Democracia y totalitarismo. Editorial DEI, San José, Costa Rica, 1987.

51. Macpherson, C. B. op. cit., p. 172. 
52. Cañas, A. Ramos, C. G. op. cit., p. 37.

53. De Soto, H. op. cit. p. 297.

54. Locke, J. Tratado del gobierno civil, citado por Macpherson. op. cit. p. 172.

55. Cañas, A. Ramos, C. G. op. cit. p. 208.

56. Vargas Llosa, M. Prólogo a De Soto, H. op. cit. p. XXVI.

57. Vargas Llosa, M. op. cit. p. XXVIII.

58. De Soto, H. op. cit. p. 284.

59. De Soto, H., Ibid.

60. Moncada, Samuel. "Derecha intelectual y grupos empresariales"; y Hinkelammert, Franz J. "Democracia y nueva derecha en América Latina"; en Nueva Sociedad. Ne 98, 1988. Se refieren ampliamente a este aspecto.

61. Moncada, Samuel. "Derecha intelectual y grupos empresariales". Ibid. p. 118.

62. Lechner, N. "acerca del ordenamiento social por medio del Estado". Revista Mexicana de Sociologia, Vol. XLIII. septiembre, 1981. p. 1085.

63. Cartaya V. F., "El confuso mundo del sector informal" Nueva Sociedad; Caracas, Venezuela, № 90, 1987. p. 80.

64. De Soto, H. op. cit., p. 59.

65. Ibid. p. 100.

66. Ibid. p. 104-109.

67. Lauer, Mirko. "Adios conservadurismo, bienvenido liberalismo", la nueva derecha en el Perú. Nueva Sociedad; Caracas, Venezuela. № 98, 1988. p. 139.

68. Ver De Soto H. op. cit. p. 227.

69. Ibid. p. 301.

70. Ibid. p. 204

71. Locke, J. op. cit. p. 5.

72. Lauer, Mirko, op. cit., p. 138.

73. Moncada, Samuel; op. cit. p. 120.

74. Vargas Llosas, M., prólogo a De Soto H. op. cit. p. XXII.

75. De Soto H. op. cit. p. 289.

76. Ibid. p. 306.

77. Ibid. p. 286.

78. Locke, J. Tratado del gobierno civil, citado por Macpherson, op. cit. p. 172.

79. Lechner, N., op. cit. p. 1082.

80. De Soto, op. cit. p. 305.

81. Cartaya, V. F. op. cit. p. 84.

82. Vargas Llosa M., prólogo a De Soto H. op. cit. p. XXXIX.

83. De Soto, H. op. cit. p. 296-7.

84. Ibid. p. 297.

85. Ibid. p. 311.

86. Ibid. p. 297.

87. Lauer, Mirko. "Adios conservadurismo, bienvenido liberalismo", op. cit. p. 135.

88. De Soto, H. op. cit. 295.

89. "La derecha rediviva". Nueva Sociedad; Caracas, Venezuela, № 98, 1988. 
p. 102.

90. Bid.

91. Hinkelammert, Franz J. "Democracia y nueva derecha en América Latina". op. cit. p. 106.

92. Ibid. p. 108.

93. Lechner, N. La conflictividad y nunca acabada construcción del orden deseado. Edic. Ainavillo, Santiago, Chile, 1984. p. 31.

94. Lechner N. "Acerca del ordenamiento de la vida social por medio del Estado". op. cit. p. 1085.

95. Vargas Llosas, M. Prólogo a De Soto, H. op. cit. P. XXI.

96. Hinkelammert, F.J. Democracia y totalitarismo. op. cit. p. 188.

97. Cañas, A. Ramos, C. G. op. cit. p. 13.

98. De Soto, H. op. cit. p. 313.

99. Hinkelammert F. J. "Democracia y nueva derecha en América Latina". op. cit. p. 108.

100. Pérez, Sáinz, J. P. Informalidad Urbana: ¿Cuál Sendero? palabra suelta № 2.

101. Cañas A. y Ramos C. G. op. cit. p. 256. 